\title{
Decisions and Coordination of Dual-Channel Supply Chain considering Retailers' Bidirectional Fairness Concerns under Carbon Tax Policy
}

\author{
Xiaodong Zhu $\mathbb{D}^{D}$, Lian Ding ${ }^{(D)}$, Yajie Guo ${ }^{(D)}$, and Huiting Zhu $(\mathbb{D}$ \\ School of Management Science and Engineering, Nanjing University of Information Science and Technology, \\ Nanjing 210044, China \\ Correspondence should be addressed to Xiaodong Zhu; zxd@nuist.edu.cn
}

Received 28 November 2021; Accepted 3 January 2022; Published 24 January 2022

Academic Editor: Xiao Xue Zheng

Copyright $(2022$ Xiaodong Zhu et al. This is an open access article distributed under the Creative Commons Attribution License, which permits unrestricted use, distribution, and reproduction in any medium, provided the original work is properly cited.

Climate change has caused huge negative impacts on the ecosystem. Carbon tax policy is an important regulatory means to reduce carbon emissions and mitigate climate change. Based on the carbon tax policy, this study discusses a dual-channel supply chain consisting of one manufacturer, one online retailer, and one offline retailer. Considering retailers' bidirectional fairness concerns, the optimal carbon emission reduction strategy and the optimal pricing strategy of centralized and decentralized decision-making are discussed under consumers' channel preference, respectively. On this basis, a coordination contract is proposed to realize the Pareto improvement of the dual-channel supply chain. We find that dual-channel retailers' profits and prices are negatively correlated with the horizontal fairness concern coefficient and positively correlated with the vertical fairness concern coefficient. The profit of the manufacturer, the carbon emission reduction, and the bargaining power of consumers are all positively correlated with the horizontal fairness concern coefficient and negatively correlated with the vertical fairness concern coefficient. Maintaining an appropriate service level can maximize the profits of enterprises and positively affect the development of enterprises. Through the coordination contract, the supply chain can be promoted to form a win-win mode of complementary advantages.

\section{Introduction}

Climate change has caused huge negative impacts on the ecosystem, such as frequent occurrences of extreme weather and mass extinctions, thus becoming one of the most urgent global challenges [1]. The main cause of climate change is excessive carbon emissions during human production. Some countries have set stage goals to control carbon emissions [2]. For example, China, the largest carbon emitter around the word, has committed to achieving a reduction in carbon emissions per unit of GDP by $60 \%-65 \%$ by 2030 compared with the level of $2005[3,4]$. The EU has committed to reducing carbon emissions in 2030 by $40 \%$ compared with the level of 1990 [5]. In order to further control carbon emissions, governments of various countries have introduced policies successively, such as carbon tax, carbon allowance, and carbon trading, among which carbon tax is the most effective in limiting carbon emissions $[6,7]$. A report on China's carbon tax by the International Monetary Fund (IMF) shows that an increase of $\$ 5$ per ton of carbon emissions per year since 2017 will reduce carbon emissions by $30 \%$ in 2030 [8]. While considering social responsibility, relevant enterprises also take into account factors such as carbon tax and carbon abatement cost that will affect the cost and profit. Therefore, carbon tax policy adds complexity to the operation of supply chain. It is of great significance to study how enterprises operate to achieve a balance between economic benefits and environmental friendliness $[9,10]$.

In the face of fierce competition in the market environment, various retailers adopt a dual-channel retail strategy of "online + offline." Online channel retailer is attracting consumers with advantages of quick response and convenience, and many enterprises have to expand online retail mode. Enterprises such as Nike, Apple, and HP have added an online channel to an offline channel. As the number of e-commerceenterprises grows, the development 
of the online retail industry has also encountered a crisis due to poor after-sales service and user experience. Many online retailers try to expand offline retail channels. Enterprises such as Xiaomi and Tmall Global are expanding offline channel while focusing on online channel. The rapid development of market economy has expanded the way of enterprises to earn profit, but the conflict in dual channel has been intensified due to the competitive relationship between online and offline channels. In the operation of dual-channel supply chain, on the one hand, it is necessary to consider corporate income while complying with the carbon tax policy. On the other hand, it is necessary to explore the internal factors that enable the dual-channel supply chain to enter a healthy and stable state.

Enterprises pay special attention to the fairness of profit distribution in the process of business dealings. When members of supply chain feel that the profit distribution is unfair, they will take retaliatory measures at the cost of losing their own profits for achieving fairness [11]. In the real business environment, there are many examples of interest conflicts caused by the subjects' fairness concern. For example, the early cooperation conflict between Wal-Mart and Procter \& Gamble due to unfair profit distribution; Gree and Gome launched a "price war" because of fairness concern. Therefore, it is necessary to introduce fairness theory into the dualchannel supply chain under carbon tax policy in order to reflect the decision-making issue among supply chain members.

A large number of scholars have researched on supply chain with fairness concern, but they all focused on the fairness concern in profit distribution between the upper and lower levels of dyadic supply chain (i.e., the supply chain consists of two parties: a manufacturer and a retailer). In this case, previous studies failed to realize how the dual-channel strategies adopted by enterprises affect the fairness issues in supply chain coordination. This paper introduces bidirectional fairness concerns into the dual-channel supply chain, and Stackelberg game is used to study the impact of both horizontal fairness concern and vertical fairness concern on the supply chain under carbon tax policy. By building a twopart tariff contract to realize the Pareto improvement of each member's profit, this paper mainly answers the following questions: (1) Under carbon tax policy, what are the optimal carbon emission reduction strategy and the optimal pricing strategy for the dual-channel supply chain? (2) What is the impact of bidirectional fairness concerns on the decisionmaking of supply chain members? (3) In view of the competitive behavior among dual-channel retailers, how does the dual-channel supply chain achieve coordination?

Under carbon tax policy, this paper studies the supply chain consisting of one manufacturer and two retailers. The contributions of this paper include following three points: (1) By studying the operating mechanism of the dualchannel supply chain, we provides references and suggestions for the manufacturer to set reasonable efforts to reduce carbon emissions. (2) Introducing the bidirectional fairness concerns into the dual-channel supply chain model, we study the impact of bidirectional fairness concerns on supply chain and provide suggestions for supply chain retailers. (3)
In order to promote the integration of dual channel's advantages, the two-part tariff contract is designed to achieve a win-win mode of complementary cooperation under complex behavior concerns.

The remainder of this article is organized as follows. Section 2 summarizes the literature. Section 3 contains the problem description and model assumption. Section 4 uses the Stackelberg game to solve the optimal strategies of the dual-channel supply chain and proposes a coordinated contract to improve the coordination of dual-channel supply chain. In Section 5, the conclusions of Section 4 are verified by numerical simulations, and sensitivity analyses of key factors are conducted. Section 6 summarizes the whole paper.

\section{Literature Review}

This study is related to three streams of literature: the carbon tax policy, the dual-channel supply chain, and the fairness concern.

Previous scholars mostly studied carbon tax policy from two perspectives of economy and environment to explore the operation strategy of supply chain. Carbon tax has been adopted by many countries and regions due to its simple management model and low management cost [12]. Ma et al. [13] discussed the impact of carbon tax policy on singlechannel supply chain's procurement strategies. Feng et al. [14] studied the impact of carbon emissions on corporate's production strategies in a two-stage single-channel supply chain. Fahimnia et al. [15] considered economic and environmental goals comprehensively and proposed a carbon tax policy plan model for single-channel supply chain. Gopalakrishnan et al. [16] studied the carbon allowance scheme among different supply chain members under carbon tax policy. Yang et al. [17] studied the impact of symmetric competition on emission reduction investment in the singlechannel supply chain. At present, most scholars focus on the impact of carbon tax policy on single-channel supply chain. Few scholars introduce carbon tax policy into dual-channel supply chain to study the impact of carbon tax policy on the dual-channel supply chain.

The research on dual-channel supply chain mainly focuses on channel selection, pricing decision, and coordination contract. Regarding channel selection, Zhou et al. [18] studied retailers' channel selection strategies under the condition of asymmetric service information. Matsui [19] studied the decision model when recycling companies have both traditional retail channels and online retail channels and compared the two retail channels. Li et al. [20] studied channel selection strategies between online retail channel and offline retail channel in the context of resource sharing. Regarding pricing decision, Rahmani and Yavari [21] studied pricing strategy and green production decision of dual-channel supply chain in the case of interrupted market demand. Qiu et al. [22] studied the joint pricing strategy and ordering plan of online and offline retail channels under the condition of uncertain demand. Regarding coordination contracts, Zheng et al. [23] studied the manufacturer's recycling channel selection mechanism and coordination contract design of dualchannel supply chain. Taleizadeh [24] considered the 
coordination contract of green supply chain based on different power structures. It is worth noting that most of the existing studies define the members of dual-channel supply chain as completely rational, but members of the supply chain are bounded rational. They not only pursue the maximization of their own profits but also pay attention to the fairness of profit distribution.

Behavioral science research has found that individuals' perceptions of fairness affect their decisions [25]. Subjects with fairness concerns measure the fairness by comparing their own profits with that of other subjects [26]. Most scholars have studied vertical fairness concern. Li et al. [27] considered the impact of subjects' vertical fairness concern on decisions and studied the impact of green levels on the investment of different types of green products. Jian et al. [28] studied the impact of vertical fairness concern on pricing and coordination mechanism of green closed-loop supply chain. Ma et al. [29] considered how retailer's vertical fairness concern affects a collection rate of closed-loop supply chain. Niederhoff and Kouvelis [30] found that the degree of fairness concern affects supplier's choice of coordination contract. A few scholars have studied horizontal fairness concern. Pan et al. [31] studied the influence of retailers' horizontal fairness concern on supply chain pricing in the dual-channel supply chain. Nie and Du [31] constructed a two-level supply chain system consisting of a single manufacturer and two retailers to analyze the impact of one retailer having horizontal fairness concern on decision making. Existing researches mostly focus on the fairness concern of profit distribution between the upper and lower levels of the vertical supply chain, without considering the horizontal fairness concern between channels in a dualchannel supply chain. This paper introduces bidirectional fairness concerns into the dual-channel supply chain and studies the impact of bidirectional fairness concerns on supply chain.

In summary, most of the existing researches focus on the impact of vertical fairness concern or carbon tax policy on the traditional single-channel supply chain. This study incorporates the carbon tax policy and bidirectional fairness concerns into the dual-channel supply chain. By constructing a dual-channel supply chain model consisting of one manufacturer, one online retailer, and one offline retailer, the optimal carbon emission reduction strategy and optimal pricing strategy are discussed, respectively. In the context of carbon tax policy and Internet economy, this paper studies enterprises how to promote the integration of channels' advantages and how to achieve a balance between environmental friendliness and economic benefits.

\section{Problem Description and Hypotheses}

3.1. Problem Description. This paper builds a dual-channel supply chain consisting of one manufacturer, one online retailer, and one offline retailer, as shown in Figure 1. The government implements carbon tax policy, and the manufacturer pays carbon tax based on the carbon emissions of their products. In addition to retailers with bidirectional fairness concerns, there is horizontal fairness concern between the two retailers, and the fairness concern coefficient is $\eta$. There is vertical fairness concern between the retailer and the manufacturer, and the vertical fairness concern coefficient is $\mu$, where $0<\eta, \mu<1$, and both are constants. $k$ and $(1-k)$ represent the consumers' channel preference for online and offline retailers.

The basic carbon emission per unit product produced by the manufacturer is $e_{\mathrm{i}}$, and carbon emission $e_{\mathrm{o}}$ can be reduced by increasing the input of carbon emission reduction. The carbon tax rate set by the government is $t$. Therefore, the carbon tax paid by the manufacturer per unit product is $t\left(e_{i}-e_{o}\right)$. The manufacturer plays a leading role in the supply chain. The manufacturer first determines the optimal wholesale price $w$ and the optimal carbon emission reduction $e_{0}$, and then online and offline retailers determine the retail prices $p_{\mathrm{o}}$ and $p_{t} . c$ is unit cost of product. Since this paper considers the dual-channel supply chain, the service level is an important factor to be considered in competitive channels. $v_{o}$ and $v_{t}$ represent the service levels provided by online and offline retailers to consumers, respectively. Specific notations are shown in Table 1.

\subsection{Assumptions}

Hypothesis 1. The manufacturer needs to invest in carbon emission reduction. The cost function is $(n / 2) e_{o}^{2}$, and $n$ is the input cost coefficient of carbon emission reduction.

Hypothesis 2. The cost functions of online and offline retailers to provide services to consumers are $(m / 2) v_{o}^{2}$ and $(m / 2) v_{t}^{2}$, and $m$ is the service cost coefficient, where $m>0$.

Hypothesis 3. The potential market size is set as $Q$, and consumers' channel preference for online retailer is set as $k$. The corresponding market demand of online and offline retail channels is recorded as $k Q$ and $(1-k) Q$, where $0<k<1$. The consumers' price sensitivity coefficient is set as $\alpha$, where $\alpha>0$. $\delta$ represents the transfer coefficient of consumers' demand to the difference in service levels. According to the research of Savaskan et al., it is assumed that demand functions of products in online and offline retail channels are $q_{o}=k Q-\alpha p_{o}+\delta\left(v_{o}-v_{t}\right)$ and $q_{t}=(1-k) Q-\alpha p_{t}+\delta\left(v_{t}-v_{o}\right)$.

Hypothesis 4. To ensure $0<q_{t}, q_{o}<Q$ and $e_{o}>0, Q-2 \alpha(c+$ $\left.e_{i} t\right)>0$ and $n>\alpha t^{2}$ must be met.

Hypothesis 5. Online and offline retailers have the same degree of fairness concern; that is, the two retailers have the same horizontal fairness concern coefficient $\eta$ and vertical fairness concern coefficient $\mu$. The larger $\eta$ and $\mu$, the greater the degree of fairness concern.

In the following, the subscripts " $m$," "o," and " $t$ " represent the manufacturer, the online retailer, and the offline retailer, respectively. The superscripts "c," "w," "n," and "x" represent centralized decision-making, decentralized decision-making under retailers' fairness concerns neutral, decentralized 


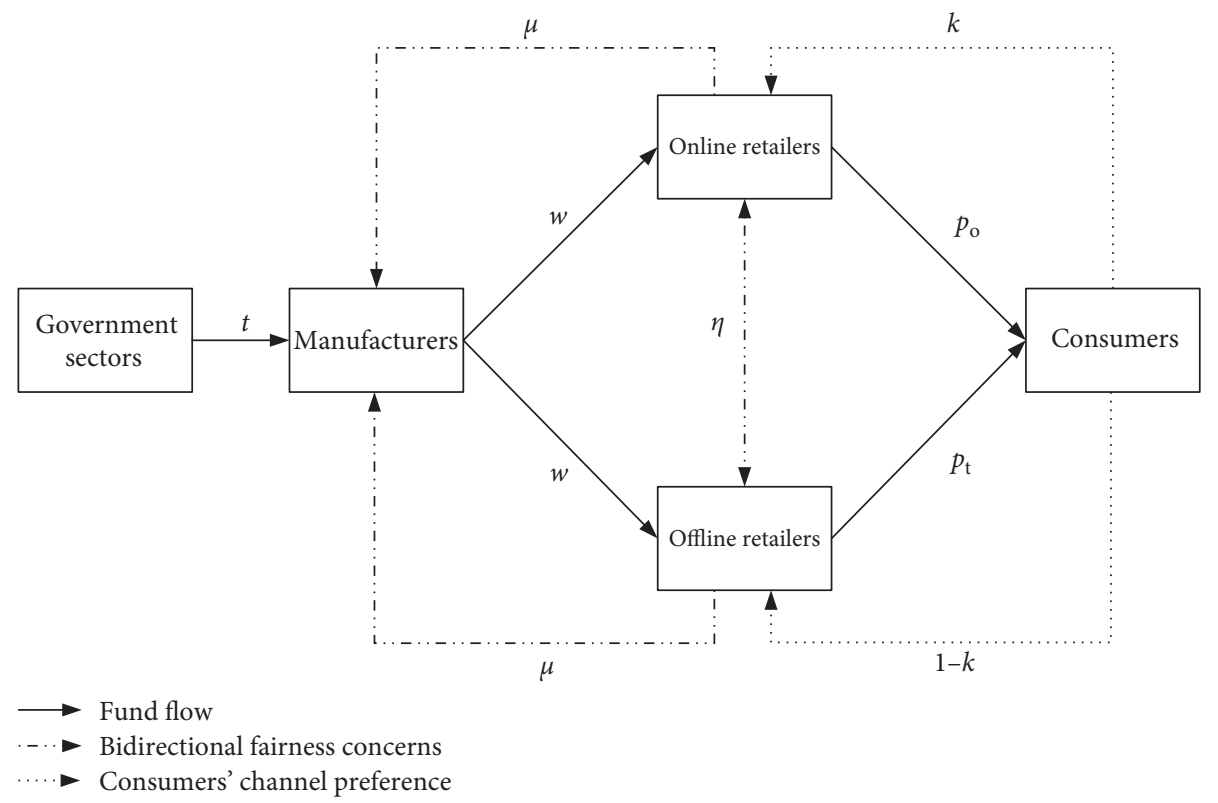

FIgURE 1: Dual-channel supply chain model.

TABle 1: Notations.

\begin{tabular}{lc}
\hline Notation & Definition \\
\hline$t$ & $\begin{array}{c}\text { Carbon tax rate imposed by the government } \\
e_{\mathrm{i}} \\
e_{\mathrm{o}}\end{array}$ \\
$n$ & The basic carbon emission per unit product produced \\
The marginal carbon emission reduction & The \\
$c$ & Input cost coefficient of carbon emission reduction \\
$Q$ & The wholesale price of the product \\
$\alpha$ & Manufacturer's production cost \\
$k$ & Potential market size \\
$m$ & The sensitivity of consumers to product's prices \\
$p_{o}, p_{t}$ & Consumers' channel preference for online retailer \\
$q_{o}, q_{t}$ & Cost coefficient of retailers' service \\
$v_{o}, v_{t}$ & Retail prices that consumers pay online and offline retailers \\
$\eta$ & Demand functions of products in online and offline retail channels \\
$\mu$ & The service level provided by online and offline retailers to consumers \\
$\delta$ & Fairness concern coefficient among horizontal supply chain members \\
$\pi_{m}, \pi_{o}, \pi_{t}$ & Fairness concern coefficient among vertical supply chain members \\
$U_{m}, U_{o}, U_{t}$ & The transfer coefficient of consumers' demand to the difference in service levels \\
\hline
\end{tabular}

decision-making under retailers with bidirectional fairness concerns, and coordination contract, respectively.

\section{Model Construction and Solution}

Based on the operating framework of the dual-channel supply chain, this chapter constructs the centralized and decentralized decision-making models and further considers the impact of retailers' bidirectional fairness concerns. This paper designs a two-part tariff contract to achieve a win-win model of complementary cooperation.

4.1. Centralized Decision-Making (Model c). Under centralized decision-making mode, a manufacturer, an online retailer, and an offline retailer cooperate with each other to jointly pursue the maximization of system profit. The optimization problem can be defined as follows:

$$
\pi_{c}^{c}=\left(p_{o}-c-t\left(e_{i}-e_{o}\right)\right) q_{o}+\left(p_{t}-c-t\left(e_{i}-e_{o}\right)\right) q_{t}-\frac{n}{2} e_{o}^{2}-\frac{m}{2}\left(v_{o}^{2}+v_{t}^{2}\right) .
$$


Theorem 1. Under centralized decision-making, the optimal retail prices, the optimal carbon emission reduction, and the optimal demands can be calculated as follows:

$$
\begin{aligned}
& p_{o}^{c}=\frac{k Q+\alpha c+\alpha t\left(e_{i}-E^{c}\right)+\delta\left(v_{o}-v_{t}\right)}{2 \alpha}, \\
& p_{t}^{c}=\frac{(1-k) Q+\alpha c+\alpha t\left(e_{i}-E^{c}\right)+\delta\left(v_{t}-v_{o}\right)}{2 \alpha}, \\
& e_{o}^{c}=\frac{2 a\left(2 a c t-Q t+2 a e_{i} t^{2}\right)}{4 a^{2} t^{2}-n}, \\
& q_{o}^{c}=\frac{1}{2}\left(k Q-\alpha c+\left(e_{i}-E^{c}\right) t\right)+\left(v_{o}-v_{t}\right) \delta, \\
& q_{t}^{c}=\frac{1}{2}\left((1-k) Q-\alpha\left(c+\left(e_{i}-E^{c}\right) t\right)+\left(v_{t}-v_{o}\right) \delta .\right.
\end{aligned}
$$

Substituting the above optimal equilibrium solutions into the objective function, the optimal profit function is obtained as follows:

$$
\pi_{c}^{c}=\frac{(1+2(-1+k) k) Q^{2}-2 a Q\left(c+\left(e_{i}-E^{c}\right) t\right)+2 a^{2}\left(c+\left(e_{i}-E^{c}\right) t\right)^{2}+2 \sigma}{4 a}-\frac{n}{2}\left(E^{c}\right)^{2}-\frac{m}{2}\left(v_{o}^{2}+v_{t}^{2}\right)
$$

To simplify the results, let $e_{o}^{i}=E^{i}(i=c, w, n, x)$, $\sigma=\left(\left(v_{o}-v_{t}\right) \delta\left((-1+2 k) Q+\left(v_{o}-v_{t}\right) \delta\right)\right)$.

\subsection{Decentralized Decision-Making}

4.2.1. Dual-Channel Retailers' Fairness Concerns Neutral (Model $w$ ). All members in the supply chain are fairness concerns neutral, and all members aim at maximizing their own profits. In this case, the decision sequence of the supply chain is as follows. First, the manufacturer determines the wholesale price and carbon emission reduction. Then, the two retailers determine the retail prices based on the manufacturer's decision. The decision models of manufacturer, online retailer, and offline retailer can be defined as follows:

$$
\begin{aligned}
& \pi_{m}^{w}=\left(w-c-t\left(e_{i}-e_{o}\right)\right)\left(q_{o}+q_{t}\right)-\frac{n}{2} e_{o}^{2} \\
& \pi_{o}^{w}=\left(p_{o}-w\right) q_{o}-\frac{m}{2} v_{o}^{2}=\left(p_{o}-w\right)\left(k Q-\alpha p_{o}+\delta\left(v_{o}-v_{t}\right)\right)-\frac{m}{2} v_{o}^{2} \\
& \pi_{t}^{w}=\left(p_{t}-w\right) q_{t}-\frac{m}{2} v_{t}^{2}=\left(p_{t}-w\right)\left((1-k) Q-\alpha p_{t}+\delta\left(v_{t}-v_{o}\right)\right)-\frac{m}{2} v_{t}^{2}
\end{aligned}
$$

Theorem 2. The optimal wholesale price, the optimal retail prices, the optimal carbon emission reduction, and the optimal demands can be calculated as follows: 


$$
\begin{aligned}
& w^{w}=\frac{Q+2 \alpha c+2 \alpha t\left(e_{i}-E^{w}\right)}{4 \alpha}, \\
& p_{o}^{w}=\frac{(1+4 k) Q+2 \alpha c+2 \alpha t\left(e_{i}-E^{w}\right)+4 \delta\left(v_{o}-v_{t}\right)}{8 \alpha}, \\
& p_{t}^{w}=\frac{(5-4 k) Q+2 \alpha c+2 \alpha t\left(e_{i}-E^{w}\right)+4 \delta\left(v_{t}-v_{o}\right)}{8 \alpha}, \\
& e_{o}^{w}=\frac{t\left(-Q+2 a\left(c+e_{i} t\right)\right)}{-4 n+2 a t^{2}}, \\
& q_{o}^{w}=\frac{1}{8}\left((4 k-1) Q-2 \alpha\left(c+\left(e_{i}-E^{w}\right) t+4\left(v_{o}-v_{t}\right) \delta\right)\right), \\
& q_{t}^{w}=\frac{1}{8}\left((3-4 k) Q-2 \alpha\left(c+\left(e_{i}-E^{w}\right) t\right)+4\left(v_{t}-v_{o}\right) \delta\right) .
\end{aligned}
$$

Substituting the above optimal equilibrium solutions into the objective functions, optimal profit functions are obtained as follows

$$
\begin{aligned}
& \pi_{m}^{w}=\frac{\left(Q-2 a\left(c+\left(e_{i}-E^{w}\right) t\right)\right)^{2}}{16 a}-\frac{n}{2}\left(E^{w}\right)^{2}, \\
& \pi_{o}^{w}=\frac{\left((1-4 k) Q+2 a\left(c+\left(e_{i}-E^{w}\right) t\right)+4\left(-v_{o}+v_{t}\right) \delta\right)^{2}}{64 a}-\frac{m}{2} v_{o}^{2}, \\
& \pi_{c}^{w}=\frac{(7+16 k(-1+k)) Q^{2}+12 a\left(c+\left(e_{i}-E^{w}\right) t\right)\left(a\left(c+\left(e_{i}-E^{w}\right) t\right)-Q\right)+16 \sigma}{32 a}-\frac{n}{2}\left(E^{w}\right)^{2}-\frac{m}{2}\left(v_{o}^{2}+v_{t}^{2}\right) \text {. } \\
& U_{m}^{n}=\pi_{m}^{n}=\left(w-c-t\left(e_{i}-E^{n}\right)\right)\left(q_{o}+q_{t}\right)-\frac{n}{2}\left(E^{n}\right)^{2}, \\
& U_{o}^{n}=\pi_{o}-\eta\left(\pi_{t}^{n}-\pi_{o}^{n}\right)-\mu\left(\pi_{m}^{n}-\pi_{o}^{n}\right), \\
& U_{t}^{n}=\pi_{t}^{n}-\eta\left(\pi_{o}^{n}-\pi_{t}^{n}\right)-\mu\left(\pi_{m}^{n}-\pi_{t}^{n}\right) .
\end{aligned}
$$$$
\pi_{t}^{w}=\frac{\left((-3+4 k) Q+2 a\left(c+\left(e_{i}-E^{w}\right) t\right)+4\left(v_{o}-v_{t}\right) \delta\right)^{2}}{64 a}-\frac{m}{2} v_{t}^{2},
$$

Theorem 3. The optimal wholesale price, the optimal retail prices, the optimal carbon emission reduction, and the optimal demands can be calculated as follows:

$$
\begin{aligned}
& w^{n}=\frac{Q(1+\eta+\mu)+2 a\left(c+\left(e_{i}-E^{n}\right) t\right)(1+\eta+3 \mu)}{4 a(1+\eta+2 \mu)}, \\
& { }_{p} n=\frac{(1+4 k) Q+2 a\left(c+\left(e_{\mathrm{i}}-E^{\mathrm{n}}\right) t\right)+4\left(v_{\mathrm{o}}-v_{\mathrm{t}}\right) \delta}{8 a}, \\
& p_{\mathrm{t}}^{n}=\frac{(5-4 k) \mathrm{Q}+2 a\left(c+\left(e_{\mathrm{i}}-E^{\mathrm{n}}\right) t\right)+4\left(-v_{\mathrm{o}}+v_{\mathrm{t}}\right) \delta}{8 a}, \\
& e_{\mathrm{o}}^{n}=\frac{t\left(-2 a\left(c+e_{\mathrm{i}} t\right)(1+\eta+\mu)+Q(1+\eta+\mu)\right)}{-2 a t^{2}(1+\eta+\mu)+4 n(1+\eta+2 \mu)}, \\
& q_{\mathrm{o}}^{n}=\frac{1}{8}\left((-1+4 k) \mathrm{Q}-2 a\left(c+\left(e_{\mathrm{i}}-E^{\mathrm{n}}\right) t\right)+4\left(v_{\mathrm{o}}-v_{\mathrm{t}}\right) \delta\right), \\
& q_{\mathrm{t}}^{n}=\frac{1}{8}\left((3-4 k) \mathrm{Q}-2 a\left(c+\left(e_{\mathrm{i}}-E^{\mathrm{n}}\right) t\right)+4\left(-v_{\mathrm{o}}+v_{\mathrm{t}}\right) \delta\right) .
\end{aligned}
$$

Substituting the above optimal equilibrium solutions into the objective functions, optimal profit and utility functions are obtained as follows: 


$$
\begin{aligned}
& \pi_{m}^{n}=U_{m}^{x}=\frac{\left(Q-2 a\left(c+\left(e_{i}-E^{n}\right) t\right)\right)^{2}(1+\eta+\mu)}{16 a(1+\eta+2 \mu)}-\frac{n}{2}\left(E^{n}\right)^{2}, \\
& \pi_{o}^{n}=\frac{\left((1-4 k) Q+2 a\left(c+\left(e_{i}-E^{n}\right) t\right)+4\left(v_{t}-v_{o}\right) \delta\right)\left(4\left(v_{t}-v_{o}\right) \delta(1+\eta+2 \mu)+Q(1+\eta-4 k(1+\eta+2 \mu))+\psi\right)}{64 a(1+\eta+2 \mu)} \\
& -\frac{m}{2} v_{o}^{2} \\
& \pi_{t}^{n}=\frac{\left((-3+4 k) Q+2 a\left(c+\left(e_{i}-E^{n}\right) t\right)+4\left(v_{o}-v_{t}\right) \delta\right)\left(4\left(v_{o}-v_{t}\right) \delta(1+\eta+2 \mu)+Q(-3-3 \eta-8 \mu+4 k(1+\eta+2 \mu))+\psi\right)}{64 a(1+\eta+2 \mu)} \\
& -\frac{m}{2} v_{t}^{2} \\
& \pi_{c}^{n}=\frac{\left(-Q+2 a\left(c+\left(e_{i}-E^{n}\right) t\right)\right)\left(\xi-4\left(v_{o}-v_{t}\right) \delta(1+\eta+3 \mu)+Q(1+\eta+5 \mu-4 k(1+\eta+3 \mu))\right)}{16 a(1+\eta+2 \mu)} \\
& -\frac{n}{2}\left(E^{n}\right)^{2}-\frac{m}{2}\left(v_{o}^{2}+v_{t}^{2}\right) \\
& U_{o}^{n}=(1+\eta+\mu)\left((A-C) D-\frac{n}{2} v_{o}^{2}\right)-\eta\left((B-F) E-\frac{n}{2} v_{t}^{2}\right) \\
& -\mu\left(F-c-t\left(e_{i}-E^{n}\right)\right)(D+E)-\frac{m}{2}\left(E^{n}\right)^{2}, \\
& U_{t}^{n}=(1+\eta+\mu)\left((B-F) E-\frac{n}{2} v_{t}^{2}\right)-\eta\left((A-C) D-\frac{n}{2} v_{o}^{2}\right) \\
& -\mu\left(\left(F-c-t\left(e_{i}-E^{n}\right)\right)(D+E)-\frac{m}{2}\left(E^{n}\right)^{2}\right) .
\end{aligned}
$$

To simplify the results, let $A=p^{n}, B=p_{t}^{n}, \quad D=q_{o}^{n}$, $E=q_{t}^{n}, F=w^{n}, \xi=2 a\left(c+\left(e_{i}-E^{n}\right) t\right)(1+\eta+\mu)$, and $\psi=$ $2 a\left(c+\left(e_{i}-E^{n}\right) t\right)(1+\eta+4 \mu)$.

Proposition 1. The wholesale price $w^{n}$ and carbon emission reduction $e_{o}$ increase with the increase of the horizontal fairness concern coefficient $\eta$ and decrease with the increase of the vertical fairness concern coefficient $\mu$.

Proposition 1 shows that when the horizontal fairness concern coefficient increases, horizontal retailers pay more attention to each other's benefits, but ignore the encroachment of the manufacturer on profits. In this case, a manufacturer's bargaining power increases, prompting the increase in wholesale price. Manufacturer has more expenditures for carbon emission reduction technology, resulting in higher carbon emission reduction. When the retailers' vertical fairness concern coefficient increases, two retailers pay more attention to the profit of the manufacturer. In this condition, online and offline retailers focus on bargaining with the manufacturer, prompting the manufacturer to reduce wholesale price. The manufacturer does not have enough time and money to spend on carbon emission reduction technology, resulting in lower carbon emission reduction.

Proposition 2. Online retail price $p_{o}$ and offline retail price $p_{t}$ decrease as the horizontal fairness concern coefficient $\eta$ increases, and increase as the vertical fairness concern coefficient $\mu$ increases.
Proposition 2 shows that when the retailers' horizontal fairness concern coefficient increases, the decisions of dualchannel retailers are more obviously affected by the profit of the other party. They hope to take the market by cutting price, which may cause a vicious competition between online and offline retailers. When the retailer's vertical fairness concern coefficient increases, the relationship between the players of the vertical supply chain becomes tense. Retailers are keen to compare their profits with the manufacturer. At this time, the bargaining power of the two retailers has increased, and the retailers increase their utilities by increasing the retail price.

Proposition 3. Comparing the retail prices of three models, we get $p_{o}^{c}<p_{o}^{w}<p_{o}^{n}, p_{t}^{c}<p_{t}^{w}<p_{t}^{n}$. Comparing the demands of three models, we get $q_{o}^{c}>q_{o}^{w}>q_{o}^{n}, q_{t}^{c}>q_{t}^{w}>q_{t}^{n}$.

Proposition 3 shows that in the competitive e-commerce environment, online and offline prices are the lowest and product sales are the highest in centralized decision-making. The retailers' bidirectional fairness concerns behavior causes the retail prices to increase again on the basis of the dual marginal effect of decentralized decision, thus leading to the decrease of sales.

Proposition 4. Whether under decentralized or centralized decision-making, when the service-level difference $v_{o}-v_{t}$ increases, $p_{o}$ increases, and $p_{t}$ decreases.

Proposition 4 shows that when the service level of one party increases, the service cost of that party increases, which 
leads to an increase in the retail price of that party. As service level and competitive edge is higher, their will maintain profits by raising prices. The other party decides to reduce the price to relieve the competitive pressure due to its reduced competitive advantage. Therefore, the service-level difference may have a different impact on different retailers' prices.

Proposition 5. Whether under decentralized or centralized decision-making, the carbon emission reduction $e_{o}$ decreases with the increase of the input cost coefficient of carbon emission reduction $n$ and increases with the increase of the potential market size Q.

Proposition 5 shows that the increase of the input cost coefficient of carbon emission reduction leads to the increase of carbon emission reduction cost, and manufacturers reduce a carbon emission reduction for the purpose of cost saving. When the market demand increases, the manufacturer needs to pay a higher carbon tax. So, the manufacturer hopes to reduce carbon tax expenses by promoting carbon emission reduction.

Proposition 6. Whether under decentralized or centralized decision-making, the carbon emission reduction $e_{o}$ increases, $w, p_{o}$, and $p_{t}$ decrease.

Proposition 6 shows that the increase of optimal carbon emission reduction means the reduction of marginal carbon emission reduction cost, which leads to the reduction of production cost of the manufacturer. While ensuring profits, the manufacturer seizes the market by reducing wholesale price. Faced with lower wholesale costs, retailers adopt the strategy of reducing retail prices, which can improve their competitive advantages and expand market demand.

4.3. Enterprise Coordination Mechanism Design. The bidirectional fairness concerns not only aggravate the double marginal effect but also lead to channel conflict, and centralized decision-making incurs high hidden management cost. Therefore, in order to make the supply chain develop toward the win-win trend of integrating advantages, this chapter constructs a coordination contract. In the coordination contract, an offline retailer provides consumers with high-quality user experience, while an online retailer provides consumers with fast information search platforms. Combining the advantages of online and offline retailers helps expand the manufacturer's sale. Therefore, this paper studies the coordination contract to promote dual-channel's advantages integration so that consumers can enjoy efficient and convenient services on the basis of eliminating the negative channel competition.

This paper constructs a two-part tariff coordination contract to realize the complementary advantages while achieving the Pareto improvement of each subjects' profits. On the one hand, the manufacturer sells products to dualchannel retailers at a lower wholesale price and charges dualchannel retailers a fixed fee as a profit guarantee. On the other hand, since an online retailer has "free rides" on the high-quality experience services provided by an offline retailer, an online retailer should bear more fixed cost. The fixed cost borne by online retailers is $(1+\theta) f$, and the fixed cost borne by the offline retailer is $(1-\theta) f$, where $0<\theta<1$. This contract can realize complementary channel advantages and eliminate the marginal utility of decentralized decisionmaking. The profit models can be defined as follows:

$$
\begin{aligned}
& \pi_{m}^{x}=\pi_{m}^{x^{\prime}}+2 f=\left(w^{x}-c-t\left(e_{i}-e_{o}\right)\right)\left(q_{o}+q_{t}\right)-\frac{n}{2} e_{o}^{2}+2 f, \\
& \pi_{o}^{x}=\pi_{o}^{x^{\prime}}-(1+\theta) f=\left(p_{o}-w^{x}\right)\left(k Q-\alpha p_{o}+\delta\left(v_{o}-v_{t}\right)\right)-\frac{m}{2} v_{o}^{2}-(1+\theta) f, \\
& \pi_{t}^{x}=\pi_{t}^{x^{\prime}}-(1-\theta) f=\left(p_{t}-w^{x}\right)\left((1-k) Q-\alpha p_{t}+\delta\left(v_{t}-v_{o}\right)\right)-\frac{m}{2} v_{t}^{2}-(1-\theta) f . \\
& \begin{array}{l}
\text { The decision models of manufacturer, online retailer, } \\
\text { and offline retailer can be defined as follows: } \\
U_{m}^{x}=\pi_{m}^{x}=\left(w^{x}-c-t\left(e_{i}-e_{o}\right)\right)\left(q_{o}+q_{t}\right)-\frac{n}{2} e_{o}^{2}+2 f, \quad(11) \\
U_{o}^{x}=\pi_{o}^{x}-\eta\left(\pi_{t}^{x}-\pi_{o}^{x}\right)-\mu\left(\pi_{m}^{x}-\pi_{o}^{x}\right),
\end{array} \\
& U_{t}^{x}=\pi_{t}^{x}-\eta\left(\pi_{o}^{x}-\pi_{t}^{x}\right)-\mu\left(\pi_{m}^{x}-\pi_{t}^{x}\right) .
\end{aligned}
$$$$
\pi_{o}^{x}=\pi_{o}^{x^{\prime}}-(1+\theta) f=\left(p_{o}-w^{x}\right)\left(k Q-\alpha p_{o}+\delta\left(v_{o}-v_{t}\right)\right)-\frac{m}{2} v_{o}^{2}-(1+\theta) f,
$$

Theorem 4. Under the coordinated contract, the optimal wholesale price, the optimal carbon emission reduction, and the optimal retail prices can be calculated as follows:

$$
\begin{aligned}
& w^{x}=\alpha\left(c+\left(e_{i}-E^{x}\right) t\right) \\
& e_{o}^{x}=e_{o}^{c}=\frac{2 a\left(2 a c_{t}-Q t+2 a e_{i} t^{2}\right)}{4 a^{2} t^{2}-n} \\
& p_{o}^{x}=p_{o}=\frac{k Q+\alpha c+\alpha t\left(e_{i}-E^{x}\right)+\delta\left(v_{o}-v_{t}\right)}{2 \alpha} \\
& p_{t}^{x}=p_{t}=\frac{(1-k) Q+\alpha c+\alpha t\left(e_{i}-E^{x}\right)+\delta\left(v_{t}-v_{o}\right)}{2 \alpha} .
\end{aligned}
$$

Under the coordination contract, the following conditions must be met to ensure that the manufacturer and retailers are willing to implement this contract, and the supply chain achieves Pareto improvement, namely: 
Proposition 7. When the two-part contract parameter $f$ meets the following condition, the perfect coordination of supply chain can be achieved. The fixed fee $f$ is determined by the negotiating power of the manufacturer and retailers.

$$
\frac{\pi_{m}^{n}-\pi_{m}^{x^{\prime}}}{2} \leq f \leq \min \left\{\begin{array}{l}
\frac{-(1+\eta+\mu)\left(\pi_{o}^{n}-\pi_{o}^{x^{\prime}}\right)+\eta\left(\pi_{t}^{n}-\pi_{t}^{x^{\prime}}\right)+\mu\left(\pi_{m}^{n}-\pi_{m}^{x^{\prime}}\right)}{1+3 \mu+\theta(1+2 \eta+\mu)}, \\
\frac{-(1+\eta+\mu)\left(\pi_{t}^{n}-\pi_{t}^{x^{\prime}}\right)+\eta\left(\pi_{o}^{n}-\pi_{o}^{x^{\prime}}\right)+\mu\left(\pi_{m}^{n}-\pi_{m}^{x^{\prime}}\right)}{1+3 \mu-\theta(1+2 \eta+\mu)}
\end{array}\right\} .
$$

\section{Numerical Simulation}

In the above chapters, this paper constructs a theoretical model of the centralized and decentralized decision-making of the dual-channel supply chain under carbon tax policy. Considering retailers' bidirectional fairness concerns, the optimal carbon emission reduction strategy and the optimal pricing strategy are discussed under consumer's channel preference, respectively. In this part, sensitivity analysis is used to study the influence of relevant parameters on carbon emission reduction, prices, and profits. Combined with the survey data on the Chinese consumer market and related literature $[33,34]$, the parameter values used in the numerical simulation are as follows: $t=0.5, e_{i}=8, n=30, c=$ $10, Q=100, \alpha=0.7, k=0.5, m=5, v_{o}=3, v_{t}=5, \eta=0.4$, $\mu=0.4$, and $\delta=1$.

5.1. The Impact of Input Cost Coefficient $n$ and Potential Market Size Q on Carbon Emission Reduction. As shown in Figure 2(a) and 2(b), under different decision-making models, the optimal carbon emission reduction decreases as the input cost coefficient of carbon emission reduction $n$ increases, and increases as the potential market size $Q$ increases. This is because as the input cost coefficient of carbon emission reduction increases, the manufacturer needs to pay more for carbon emission reduction cost. The tax compensation brought by the huge cost input is negligible. Therefore, the manufacturer cuts costs by downgrading carbon emission reduction. On the contrary, as the potential market size increases, the willingness of the manufacturer to reduce carbon tax has been intensified. The manufacturer hopes to reduce tax expenditures by increasing the amount of carbon emission reduction. In summary, the manufacturer should work hard to develop carbon emission reduction technology to reduce the input cost coefficient of carbon emission reduction. At the same time, the manufacturer should expand the market and achieve the effect of reducing carbon emissions and protecting the environment.

5.2. The Impact of Service Levels $v_{o}$ and $v_{t}$ on Prices and Profits. As shown in Figures 3(a) and 3(b), when the service level increases, the retail price of that party rises accordingly. This is because a higher service level will increase the service cost of that party. The other party is in a disadvantaged position due to the low level of service and decides to reduce the price to alleviate the pressure of competition. Therefore, the retail price of one party is inversely proportional to the other party's service level.

As shown in Figures 3(c) and 3(d), for retailers of different channels, when one party's service level increases, the party's profit first increases and then decreases. When the service level starts increasing, the party's profit increases with the increase of the service level. This is because the improvement of the service level brings consumers a better user experience, which in turn attracts more consumers. But when the service level raised to a certain level, and the profit of the retail channel reaches the maximum value, the profit will show a downward trend because too high service level costs high costs, which in turn may lead to a decline in profit. In the process of product sales, enterprises should reasonably control their service level based on their actual conditions and industry environment. It is unwise to blindly improve the service level and ignore the balance between service-level costs and benefits.

\subsection{The Impact of Bidirectional Fairness Concerns Coefficient on Supply Chain}

5.3.1. The Impact of Bidirectional Fairness Concerns $\eta$ and $\mu$ on Wholesale Price. It can be seen from Figure 4 that the wholesale price under retailers with bidirectional fairness concerns is lower than the wholesale price under retailers' bidirectional fairness concerns neutral, which shows that bidirectional fairness concerns of retailers are conducive to increasing retailers' bargaining power to the manufacturer on the whole. The wholesale price is directly proportional to the horizontal fairness concern coefficient and inversely proportional to the vertical fairness concern coefficient. This shows that the stronger the horizontal fairness concern, the more horizontal retailers pay more attention to each other's benefits, ignoring the cannibalization of profits by the manufacturer. And the stronger the vertical fairness concern, the stronger the bargaining power of retailers to the manufacturer.

5.3.2. The Impact of Bidirectional Fairness Concerns $\eta$ and $\mu$ on Prices. As can be seen from Figures 5(a) and 5(b), online and offline prices have basically the same changing trends under dual-channel retailers with bidirectional fairness 


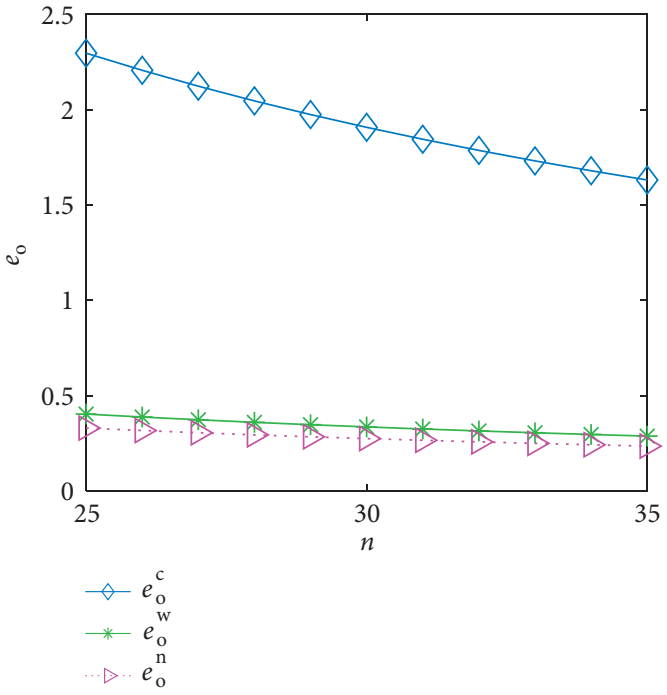

(a)

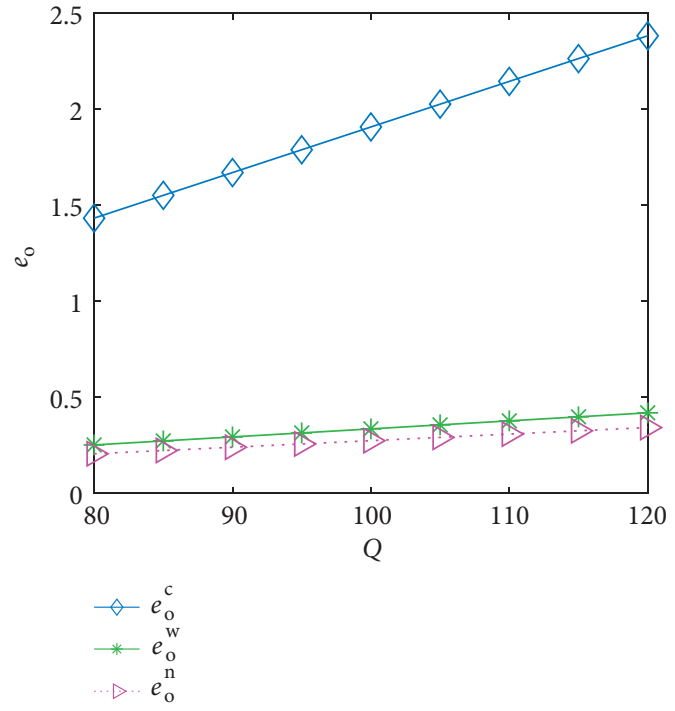

(b)

Figure 2: The impact of input cost coefficient $n$ and potential market size $Q$ on carbon emission reduction $e_{o}$. (a) The influence of input cost coefficient $n$ on carbon emission reduction $e_{\mathrm{o}}$. (b) The influence of potential market size $Q$ on carbon emission reduction $e_{0}$.
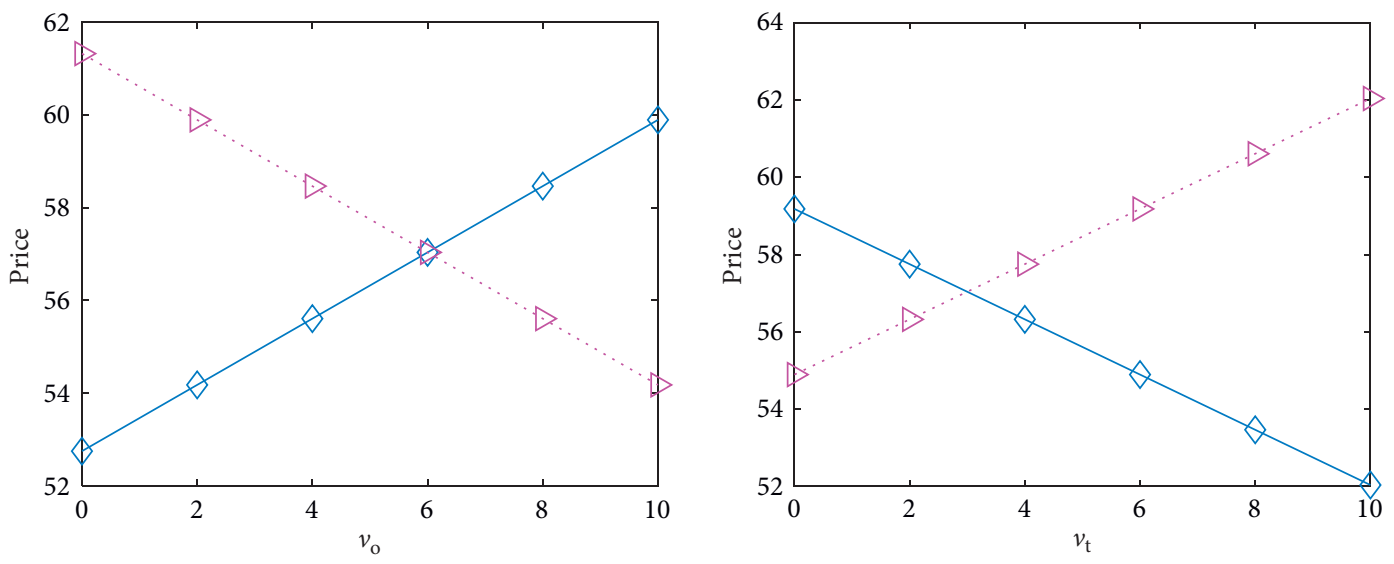

$$
\begin{aligned}
& \diamond p^{\mathrm{o}} \\
& \triangleright p^{\mathrm{n}}
\end{aligned}
$$

$$
\begin{array}{r}
\diamond p^{\mathrm{o}} \\
\triangleright p^{\mathrm{n}}
\end{array}
$$

(a)

(b)

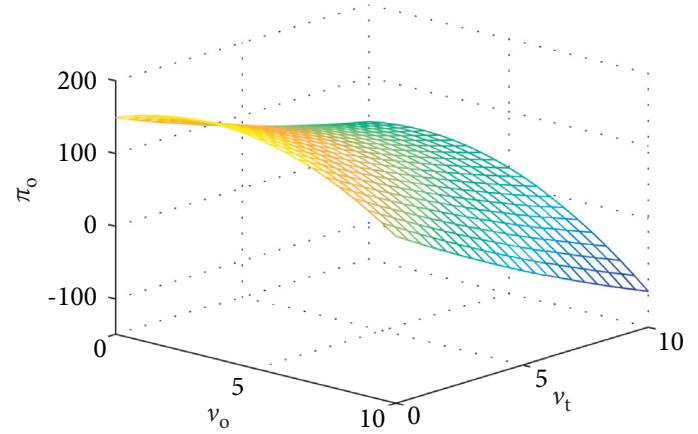

(c)

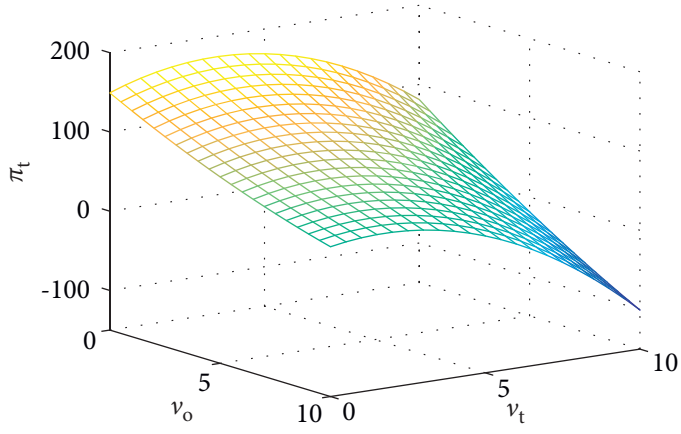

(d)

Figure 3: The impact of service levels $v_{\mathrm{o}}$ and $v_{\mathrm{t}}$ on prices and profits. (a) The impact of the service level of the online retailer $v_{\mathrm{o}}$ on the price of online and offline retailers. (b) The impact of the service level of the offline retailer $v_{t}$ on the price of online and offline retailers. (c) The impact of service levels $v_{\mathrm{o}}$ and $v_{\mathrm{t}}$ on online retailer's profit. (d) The impact of service levels $v_{o}$ and $v_{t}$ on offline retailer's profit. 


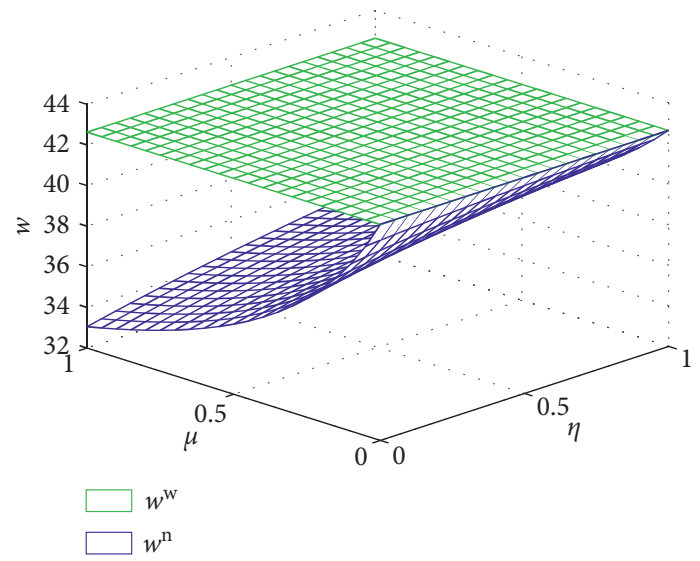

Figure 4: The impact of bidirectional fairness concerns' coefficient on wholesale prices.

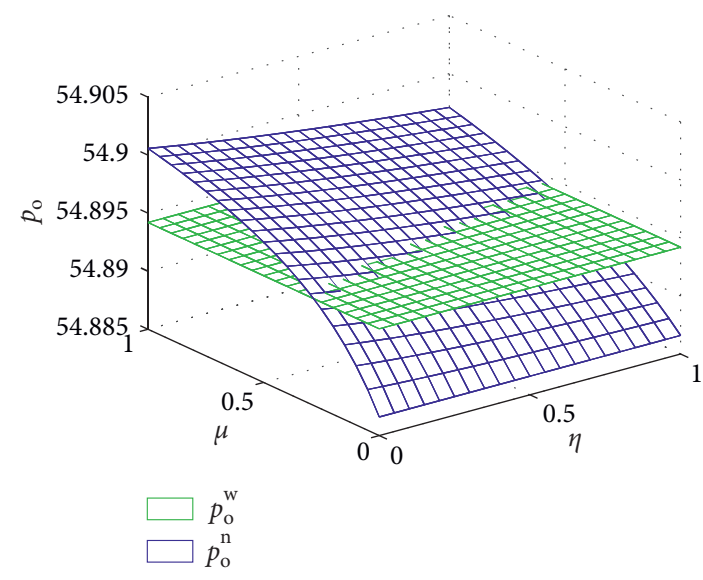

(a)

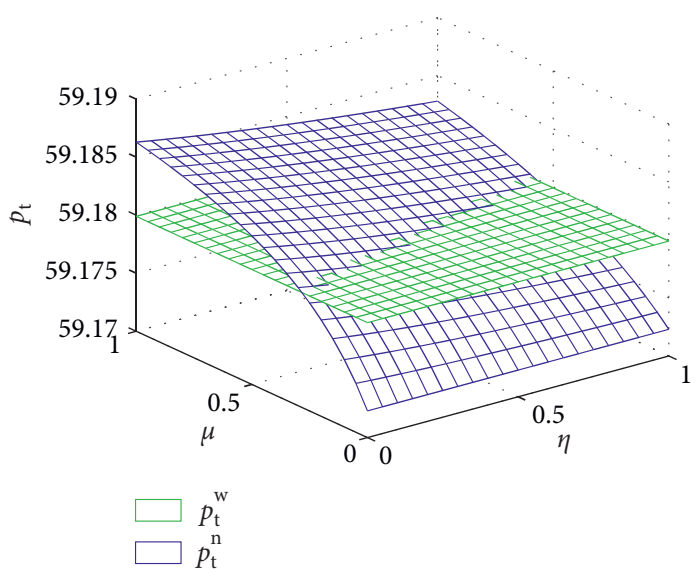

(b)

FIGURE 5: The impact of bidirectional fairness concerns' coefficient on prices. (a) The impact of bidirectional fairness concerns' coefficient on online price. (b) The impact of bidirectional fairness concerns' coefficient on offline price.

concerns. When the vertical fairness concern coefficient is in a large range, the retail prices under retailers with bidirectional fairness concerns are greater than the retail prices when the retailers are fair neutrality. When the vertical fairness concern coefficient is small and the horizontal fairness concern coefficient is large, the retail prices under retailers with bidirectional fairness concerns are lower than the retail prices when the retailers are fair neutrality.

\subsubsection{The Impact of Bidirectional Fairness Concerns $\eta$ and $\mu$} on Profits. From Figure 6(a), it can be concluded that the manufacturer's profit is directly proportional to the horizontal fairness concern coefficient and inversely proportional to the vertical fairness concern coefficient. The stronger the retailers' horizontal fairness concern, the stronger the manufacturer's dominant advantages, and thus more benefits. The stronger the retailers' vertical fairness concern, the weaker the manufacturer's dominant advantage, resulting in lower profit for the manufacturer than in the case of retailers' fairness concerns neutral.

From Figures 6(b) and 6(c), it can be concluded that profits obtained by online and offline retailers are inversely proportional to the horizontal fairness concern coefficient and directly proportional to the vertical fairness concern coefficient. This shows that vertical fairness concerns are conducive to the retailer to obtain more profits, while horizontal fairness concern will cause damage to both online and offline retailers. At the same time, two retailers are willing to sacrifice part of their own profits to maximize their fairness.

5.3.4. The Impact of Bidirectional Fairness Concerns $\eta$ and $\mu$ on Utilities. As can be seen from Figure 7, under dualchannel retailers with bidirectional fairness concerns, horizontal fairness concern of dual-channel retailers promotes the increase of manufacturer's utility. In this case, competition among horizontal retailers intensified, and retailers ignored the manufacturers' cannibalization of profits. The utilities of online and offline retailers decrease with the increase of bidirectional fairness concern coefficients. It can be seen that retailers' fairness concerns have a negative effect on their own utility. Therefore, it is necessary to design a coordination contract to promote the integration of advantages of dual-channel retailers. 


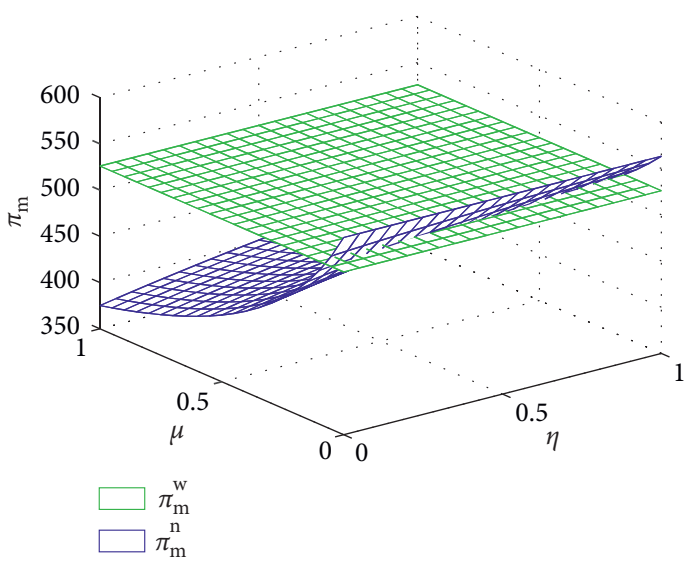

(a)

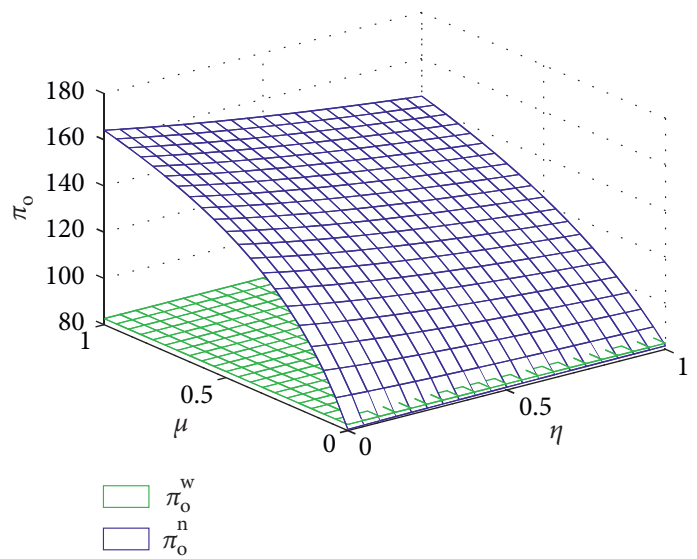

(b)

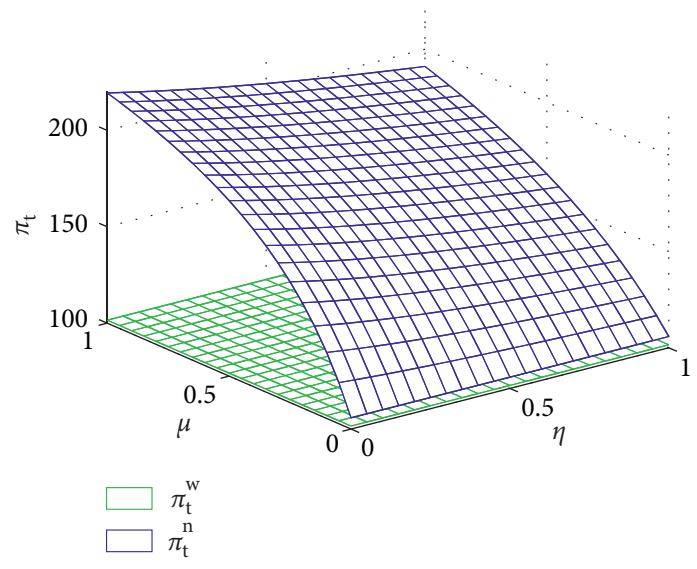

(c)

Figure 6: The impact of bidirectional fairness concerns coefficient on profits. (a) The impact of bidirectional fairness concerns coefficient on manufacturer's profit. (b) The impact of bidirectional fairness concerns' coefficient on online retailer's profit. (c) The impact of bidirectional fairness concerns' coefficient on offline retailer's profit.

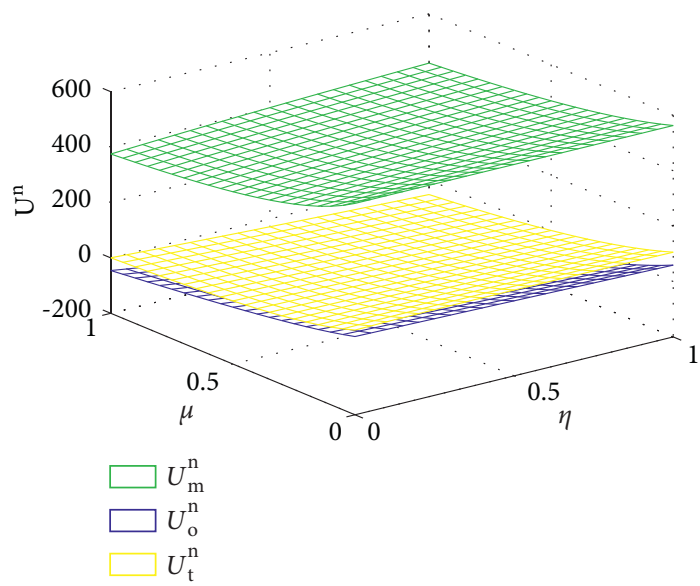

FIgURE 7: The impact of bidirectional fairness concerns' coefficient on utilities. 


\section{Conclusion}

Under carbon tax policy, this paper constructs a dualchannel supply chain consisting of one manufacturer and two retailers from the perspective of game theory and behavior theory. Considering online and offline retailers' bidirectional fairness concerns, the optimal carbon emission reduction strategy and the optimal pricing strategy of centralized and decentralized decision-making are discussed, respectively. Through sensitivity analysis, we discuss the influence of bidirectional fairness concerns, service levels, and other factors on decisions:

(1) For the manufacturer, the optimal carbon emission reduction and the optimal wholesale price are positively correlated with horizontal fairness concern coefficient and negatively correlated with vertical fairness concern coefficient. Within a certain threshold range, the increase of horizontal fairness concern coefficient will lead to the improvement of manufacturer's profit, while the increase of vertical fairness concern coefficient will lead to the disharmony between upper and lower levels of the supply chain and ultimately lead to the decrease of manufacturer's profit. Manufacturer should maintain good relationship with retailers and reduce the profit loss caused by vertical competition. At the same time, the manufacturer can consciously develop multiple retailers and promote the competition among retailers to increase their own profits.

(2) Under different decision-making models, the optimal carbon emission reduction is inversely proportional to the input cost coefficient of carbon emission reduction and directly proportional to the potential market size. As the input cost coefficient increases, the cost of carbon emission reduction increases. The carbon tax offset from higher cost inputs is negligible. Therefore, the manufacturer chooses to reduce carbon emission reduction to reduce cost. As the total market demand increases, the manufacturer has to pay more carbon tax. The manufacturer can reduce tax expenditures by increasing the amount of carbon emission reduction.

(3) The retail prices of the dual channel are negatively correlated with the horizontal fairness concern coefficient and positively correlated with the vertical fairness concern coefficient. The increase of horizontal fairness concern results in intensified competition between online and offline retailers, and both sides will adopt a low price strategy to seize the market. Blind competition between the two parties leads to the reduction of their benefits, respectively. With the increase of vertical fairness concern, retailers are keen to compare their profits with the manufacturer. Retailers try to increase their profits by raising the retail price so as to obtain higher fair utilities.
(4) Service level is an important factor for retail enterprises to consider. For different retail channels, when the service level is improved, the retail prices of the corresponding channel will rise correspondingly, and the profit will rise first and then decline. The other party will take the strategy of price reduction to compete in the market and the profit keeps decreasing. Relevant enterprises should pay attention to the development status of service level and control appropriate service level, too high or too low service level will damage the profits of enterprises.

(5) Coordination contract can avoid channel conflict between different retailers and realize a pareto improvement of supply chain. By reducing wholesale price, the manufacturer can expand sales and gain economies of scale. Online and offline retailers bear different proportions of fixed cost, which can realize the integration of advantages of different channels while alleviating the unfair effect brought by online retailers' free-riding behavior. Through coordination contract, a dual-channel supply chain can achieve the win-win mode of complementary cooperation so that consumers can enjoy efficient and convenient services on the basis of eliminating the negative channel competition.

In view of the above conclusions, this paper puts forward the following suggestions:

(1) Government should make efforts to promote the manufacturer to develop carbon emission reduction technology and reduce the input cost coefficient of carbon emission reduction. Meanwhile, the manufacturer and retailers should strengthen market expansion, so as to reduce carbon emissions and relieve ecological pressure.

(2) Manufacturer should establish cooperative and winwin partnership with dual-channel retailers in the process of operation. If they only pay one-sided attention to own price, their profits will be lost. Similarly, retailers of different channels should pay attention to complementing each other's advantages in the operation process to improve profits of both sides.

(3) In the process of operation, retailers should combine the industry environment with their own actual situations to maintain appropriate service levels, ensuring the balance between service level and service cost.

\section{Data Availability}

The data used to support the findings of this study are included within the article.

\section{Conflicts of Interest}

The authors declare that they have no conflicts of interest. 


\section{Acknowledgments}

This paper received administrative and technical support from the China Institute of Manufacturing Development. This research was funded by the Major Project of Philosophy and Social Science Research in Colleges and Universities in Jiangsu Province (Grant No. 2021SJZDA131), the Postgraduate Research and Practice Innovation Program of Jiangsu Province (Grant No. KYCX21_1039), and the Ministry in China of Education of Humanities and Social Science Project (Grant No. 19YJC630240).

\section{References}

[1] S. Xu, L. Fang, and K. Govindan, "Energy performance contracting in a supply chain with financially asymmetric manufacturers under carbon tax regulation for climate change mitigation," Omega, vol. 106, Article ID 102535, 2022.

[2] G. Zhang, P. Cheng, H. Sun, Y. Shi, G. Zhang, and A. Kadiane, "Carbon reduction decisions under progressive carbon tax regulations: a new dual-channel supply chain network equilibrium model," Sustainable Production and Consumption, vol. 27, pp. 1077-1092, 2021.

[3] C. Duan, B. Chen, K. Feng et al., "Interregional carbon flows of China," Applied Energy, vol. 227, pp. 342-352, 2018.

[4] Y.-J. Zhang, J.-Y. Liu, and B. Su, "Carbon congestion effects in China's industry: evidence from provincial and sectoral levels," Energy Economics, vol. 86, Article ID 104635, 2020.

[5] R. Mateus, S. M. Silva, and M. G. de Almeida, "Environmental and cost life cycle analysis of the impact of using solar systems in energy renovation of Southern European single-family buildings," Renewable Energy, vol. 137, pp. 82-92, 2019.

[6] B. Liu, M. Holmbom, A. Segerstedt, and W. Chen, "Effects of carbon emission regulations on remanufacturing decisions with limited information of demand distribution," International Journal of Production Research, vol. 53, no. 2, pp. 532-548, 2015.

[7] H. Yang and W. Chen, "Retailer-driven carbon emission abatement with consumer environmental awareness and carbon tax: revenue-sharing versus Cost-sharing," Omega, vol. 78, pp. 179-191, 2018.

[8] I. Parry and P. Wingender, "The overwhelming case for a carbon tax in China," 2016, https://blogs.imf.org/2016/07/27/ the-overwhelming-case-for-a-carbon-tax-in-china/.

[9] Z. Liu, K. W. Li, J. Tang, B. Gong, and J. Huang, "Optimal operations of a closed-loop supply chain under a dual regulation," International Journal of Production Economics, vol. 233, Article ID 107991, 2021.

[10] X. Hong, L. Xu, P. Du, and W. Wang, "Joint advertising, pricing and collection decisions in a closed-loop supply chain," International Journal of Production Economics, vol. 167, pp. 12-22, 2015.

[11] T. Li, J. Xie, X. Zhao, and J. Tang, "On supplier encroachment with retailer's fairness concerns," Computers \& Industrial Engineering, vol. 98, pp. 499-512, 2016.

[12] S. Song, K. Govindan, L. Xu, P. Du, and X. Qiao, "Capacity and production planning with carbon emission constraints," Transportation Research Part E: Logistics and Transportation Review, vol. 97, pp. 132-150, 2017.

[13] X. Ma, P. Ji, W. Ho, and C.-H. Yang, "Optimal procurement decision with a carbon tax for the manufacturing industry," Computers \& Operations Research, vol. 89, pp. 360-368, 2018.
[14] Y. Feng, J. Shen, and X. Li, "Pricing and carbon emission reduction decisions in a supply chain with a risk-averse retailer under carbon tax regulation," Mathematical Problems in Engineering, vol. 2020, Article ID 5351867, 2020.

[15] B. Fahimnia, J. Sarkis, A. Choudhary, and A. Eshragh, "Tactical supply chain planning under a carbon tax policy scheme: a case study," International Journal of Production Economics, vol. 164, pp. 206-215, 2015.

[16] S. Gopalakrishnan, D. Granot, F. Granot, G. Sošić, and H. Cui, "Incentives and emission responsibility allocation in supply chains," Management Science, vol. 67, no. 7, pp. 4172-4190, 2021.

[17] L. Yang, Q. Zhang, and J. Ji, "Pricing and carbon emission reduction decisions in supply chains with vertical and horizontal cooperation," International Journal of Production Economics, vol. 191, pp. 286-297, 2017.

[18] R. Zhou, Y. Liao, W. Shen, and S. Yang, "Channel selection and fulfillment service contracts in the presence of asymmetric service information," International Journal of Production Economics, vol. 222, p. 107504, 2020.

[19] K. Matsui, "Optimal timing of acquisition price announcement for used products in a dual-recycling channel reverse supply chain," European Journal of Operational Research, 2021, In press.

[20] G. Li, X. Zhang, S.-M. Chiu, M. Liu, and S. P. Sethi, "Online market entry and channel sharing strategy with direct selling diseconomies in the sharing economy era," International Journal of Production Economics, vol. 218, pp. 135-147, 2019.

[21] K. Rahmani and M. Yavari, "Pricing policies for a dualchannel green supply chain under demand disruptions," Computers \& Industrial Engineering, vol. 127, pp. 493-510, 2019.

[22] R. Qiu, L. Hou, Y. Sun, M. Sun, and Y. Sun, "Joint pricing, ordering and order fulfillment decisions for a dual-channel supply chain with demand uncertainties: a distribution-free approach," Computers \& Industrial Engineering, vol. 160, Article ID 107546, 2021.

[23] B. Zheng, J. Chu, and L. Jin, "Recycling channel selection and coordination in dual sales channel closed-loop supply chains," Applied Mathematical Modelling, vol. 95, pp. 484-502, 2021.

[24] A. A. Taleizadeh, N. Alizadeh-Basban, and B. R. Sarker, "Coordinated contracts in a two-echelon green supply chain considering pricing strategy," Computers \& Industrial Engineering, vol. 124, pp. 249-275, 2018.

[25] D. Corsten and N. Kumar, "Do suppliers benefit from collaborative relationships with large retailers? An empirical investigation of efficient consumer response adoption," Journal of Marketing, vol. 69, no. 3, pp. 80-94, 2005.

[26] Z. Liu, X.-X. Zheng, D.-F. Li, C.-N. Liao, and J.-B. Sheu, “A novel cooperative game-based method to coordinate a sustainable supply chain under psychological uncertainty in fairness concerns," Transportation Research Part E: Logistics and Transportation Review, vol. 147, Article ID 102237, 2021.

[27] Q. Li, X. Guan, T. Shi, and W. Jiao, "Green product design with competition and fairness concerns in the circular economy era," International Journal of Production Research, vol. 58, no. 1, pp. 165-179, 2020.

[28] J. Jian, B. Li, N. Zhang, and J. Su, "Decision-making and coordination of green closed-loop supply chain with fairness concern," Journal of Cleaner Production, vol. 298, Article ID 126779, 2021.

[29] P. Ma, K. W. Li, and Z.-J. Wang, "Pricing decisions in closedloop supply chains with marketing effort and fairness 
concerns," International Journal of Production Research, vol. 55, no. 22, pp. 6710-6731, 2017.

[30] J. A. Niederhoff and P. Kouvelis, "Generous, spiteful, or profit maximizing suppliers in the wholesale price contract: a behavioral study," European Journal of Operational Research, vol. 253, no. 2, pp. 372-382, 2016.

[31] K. Pan, Z. Cui, A. Xing, and Q. Lu, "Impact of fairness concern on retailer-dominated supply chain," Computers \& Industrial Engineering, vol. 139, Article ID 106209, 2020.

[32] T. Nie and S. Du, "Dual-fairness supply chain with quantity discount contracts," European Journal of Operational Research, vol. 258, no. 2, pp. 491-500, 2017.

[33] P. Toktaş-Palut, "An integrated contract for coordinating a three-stage green forward and reverse supply chain under fairness concerns," Journal of Cleaner Production, vol. 279, Article ID 123735, 2021.

[34] Y. Wang, Z. Yu, M. Jin, and J. Mao, "Decisions and coordination of retailer-led low-carbon supply chain under altruistic preference," European Journal of Operational Research, vol. 293, no. 3, pp. 910-925, 2021. 